\title{
EFFECT OF FENTANYL ON PENDULAR ROTATION NYSTAGMUS IN SQUIRREL MONKEYS*
}

\author{
JIN KANZAKI, MAKOTO IGARASHI, ${ }^{* *}$ HIDEO MIYATA*** \\ and W. K. WRIGHT** \\ Department of Otolaryngology, School of Medicine, \\ Keio University, Tolyo, Japan
}

(Received for publication June 15, 1973)

\begin{abstract}
Pendular rotation nystagmus was repeatedly investigated in squirrel monkeys after injecting Fentanyl in different doses. Good nystagmic inhibition was observed although the slow phase eye movement remained after more than $0.027 \mathrm{mg} / \mathrm{kg}$ of the drug was administered. Sequential tests demonstrated the pattern of nystagmic suppression and its recovery along the post-injection time course.
\end{abstract}

As a neuroleptoanalgesia, the combination of Fentanyl and Droperidol (Innovar ( $(\mathbb{B})$ is widely used especially in the surgical field. Also, there is a report describing the effect of Droperidol-Fentanyl citrate for Meniere's disease (Dowdy et al, 1965). This particular combination inhibits alcohol induced nystagmus (Vancil et al, 1969) and also inhibits symptomatic spontaneous nystagmus in many different diseases (Boedts and Vandenhove, 1969). On the other hand, in humans, Dowdy has described very little inhibitory effect on caloric nystagmus when Fentanyl or Droperidol was used separately. However, after Fentanyl administration to rabbits, selective inhibition of the quick phase nystagmus eye movement, which was evoked by torision swing or "bar-b-que" rotation. was reported by Janeke and others (1969). The pharmaceutical effect, however, may have been different according to the dose administered and also

* This study was supported in part by the McFadden Trust Research Fund, NIH grants NS-07237, KO3-NS-38619, and PO1-NS-10940.

** Department of Otolaryngoloby, Baylor College of Medicine, Houston, Texas, U.S.A.

*** Department of Otolaryngology, Gifu University School of Medicine, Gifu, Japan. 
by the testing procedure.

In the present investigation, using squirrel monkeys, the effect of Fentanyl upon the nystagmic eyeball movement, evoked by pendular rotation stimulation, was studied sequentially after the drug was administered.

\section{PROCEDURE}

Seven healthy squirrel monkeys (Saimiri sciureus), about one and one-half years old (with no preference as to their sex) were used for the present investigation. Their body weights ranged from $460 \sim 590$ grams.

A modified pendular rotation table which was suspended by four metal wires from an $\mathbf{1 1}$ foot ceiling was used. The monkey was restrained in a sitting position and placed at the co-axial center of the table. The suspended table was rotated $225^{\circ}$ to the right of its original, neutral position and released. The initial cycle of pendular oscillation took $12 \sim 14$ seconds. The rotation decelerated gradually, and after five to six oscillations, the table stopped spontaneously. By utilizing electronystagmographic recordings, perrotatory nystagmus was recorded with the head covered. Platinum subdermal needle electrodes were used and nystagmic recordings were obtained through a four-channel polygraph recorder (DC recording). Simultaneous horizontal and vertical inductions were recorded.

The animal's alertness was maintained by applying additional external stimuli, such as pinching his tail. Before the injection, each subject was repeatedly tested (by pendular rotation) to determine normal vestibular function.

Sublimaze (Fentanyl citrate) was injected intramuscularly with varying doses of $0.018 \sim 0.045 \mathrm{mg} / \mathrm{kg}$. The post injection examination was repeatedly performed following the time course until the subject showed good recovery in response. Three normal subjects without any injection were also repeatedly tested according to the same testing sequences.

When pendular rotation nystagmus declined for a certain period after the Fentanyl injection, $3 \mathrm{ml}$ of ice water was introduced into the left external auditory canal (within five seconds) to ensure the decline of response (four cases).

\section{FINDINGS}

Variable data were obtained, including the complete suppression of nystag- 
mus and partial reduction of nystagmic frequency, etc. Complete inhibition of nystagmus was not observed in two cases after 0.018 and $0.026 \mathrm{mg} / \mathrm{kg}$.

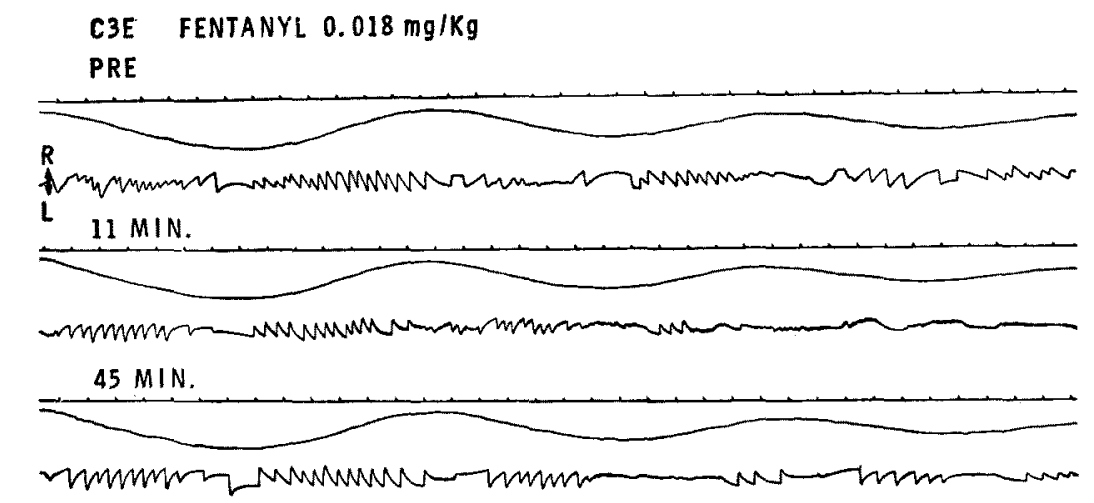

Fig. 1 Sequential recordings of the nystagmus demonstrate the condition after Fentanyl $0.018 \mathrm{mg} / \mathrm{kg}$ had been injected. A slight change of nystagmus is noticed eleven minutes after the injection.

Table 1

\begin{tabular}{|c|c|c|c|c|c|c|c|c|c|c|c|}
\hline & \multirow{2}{*}{$\begin{array}{c}\text { Doses } \\
(\mathrm{mg} / \mathrm{kg})\end{array}$} & \multirow{2}{*}{$\begin{array}{l}\text { Pre- } \\
\text { Inj. }\end{array}$} & \multicolumn{9}{|c|}{ Post-injection (minutes) } \\
\hline & & & 5 & 10 & 15 & 20 & 30 & 45 & 60 & 90 & 120 \\
\hline C2D & 0.045 & $3_{* *}$ & 0 & 0 & $-*$ & & 0 & & $0_{*}$ & 1 & $3_{-*}$ \\
\hline $\mathrm{C} 4 \mathrm{C}$ & 0.033 & $3_{* *}$ & 2 & 1 & ${ }_{-*}^{0}$ & 0 & 0 & 0 & $0_{-}^{*}$ & 3 & \\
\hline B9B & 0.030 & 3 & 1 & 1 & 0 & & 0 & 0 & 0 & 2 & 3 \\
\hline C3B & 0.027 & 3 & 1 & 1 & & 1 & 0 & 1 & 3 & & \\
\hline C3C & 0.026 & $3_{* *}$ & 2 & 2 & 2 & & $1_{*}$ & 1 & 2 & 3 & \\
\hline C4A & 0.021 & $3_{* * *}$ & 1 & $*$ & 0 & _* $^{*}$ & 0 & 1 & ${ }^{2}-*$ & & 3 \\
\hline C3E & 0.018 & 3 & 3 & 3 & 2 & 2 & 3 & 3 & & & \\
\hline
\end{tabular}

The numbers in this table indicate the pendular rotation nystagmus along the postinjection time course. 3: normal, 2: moderate reduction, 1: severe reduction, 0: no response. Asterisks demonstrate the caloric responses obtained. **: normal response, *: reduced response, -*; no response. 


\section{C3B FENTANYL $0.027 \mathrm{mg} / \mathrm{Kg}$}

PRE

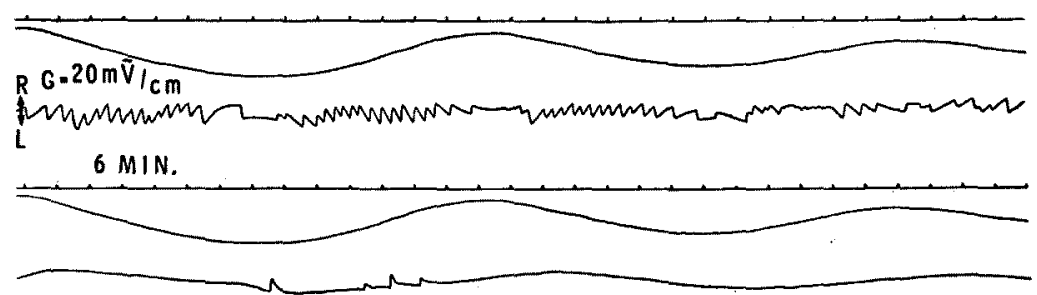

21 MIN.

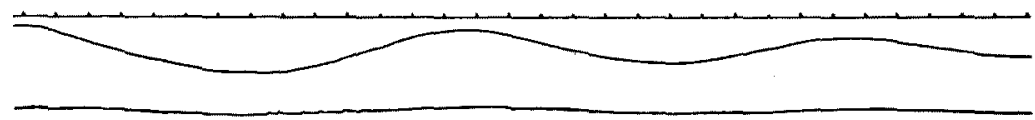

$62 M I N$.

$6.50 \mathrm{mV} / \mathrm{cm}$

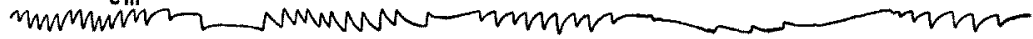

Fig. 2 Pendular rotation nystagmus recordings demonstrate the condition after Fentanyl $0.027 \mathrm{mg} / \mathrm{kg}$ had been injected. A significant reduction of nystagmic frequency is observed even six minutes after the injection.

B9 B FENTANYL $0.03 \mathrm{mg} / \mathrm{Kg}$

PRE

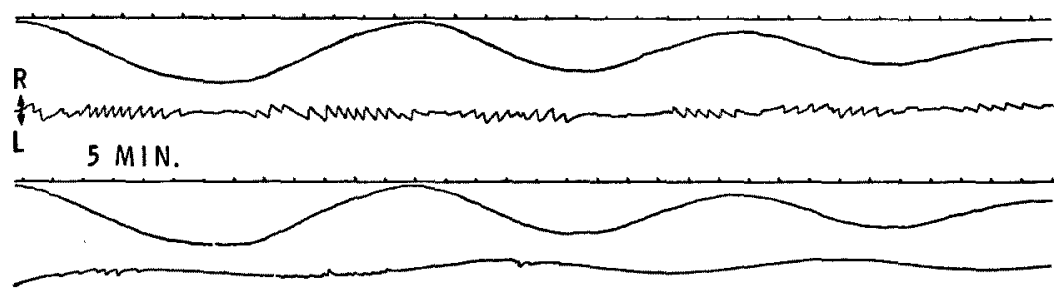

25 MIN.

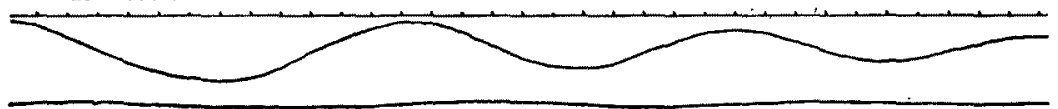

89 MIN.

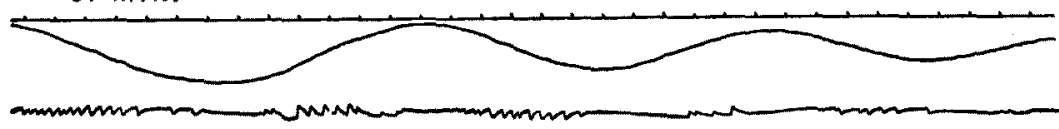

Fig. 3 This series of nystagmus recordings exhibit the conditions after Fentanyl $0.03 \mathrm{mg} / \mathrm{kg}$ had been injected. A reduction in frequency and amplitude of the nystagmus is noticed five minutes after the injection. Some persistent reduction can be noticed even 90 minutes after the injection. 
(Figure 1). However, total inhibition was found in all other subjects, and it was especially clear for a long time period when the doses were $0.030 \mathrm{mg} / \mathrm{kg}$ or more (Table 1). Figures 2 and 3 reveal the characteristics of the nystagmus suppression and recovery along the time course in two representative cases.

The variation in the latent period before the nystagmic suppression, peak inhibition time and its duration, and the time period required for recovery were all dependent upon the administered doses and certainly upon inter-individual variance. After more than $0.021 \mathrm{mg} / \mathrm{kg}$ doses, only a short time (five minutes) was needed before nystagmic inhibition could be observed. One animal that received a dose of $0.045 \mathrm{mg} / \mathrm{kg}$ showed complete nystagmic inhibition five minutes after the injection. Also, in the cases with nystagmic inhibition, 60 120 minutes were required to recover the pre-injection status.

As long as nystagmus was observed, no clear change in nystagmic wave form was found using the present test procedures. When nystagmus was significantly inhibited, slight sinusoidal eye-deviation was observed in most cases.

The effect of Fentanyl administration on caloric nystagmus responses was either disappearance of the nystagmus, or nystagmic inhibition (mainly the number of nystagmic beats). The results from the caloric test were generally in agreement with those from the pendular rotation test, although two cases (C2D and C4C) showed some discrepancy; caloric response showed reduction 90 and 120 minutes respectively after Fentanyl administration, while pendular rotation nystagmus by that time had made good recovery (Table 1 ).

Three monkeys without injection did not exhibit any significant nystagmic decline during the series of the tests; however, one subject showed a slight reduction which may represent a fatigue effect.

\section{COMMENT}

The nystagmic inhibitory effect of Fentanyl injection was observed both in pendular rotation tests and caloric tests in the present squirrel monkey studies. Some difference between our experimental results and the results obtained by other investigators (Janeke et al, 1969; Harris et al, 1969) may be due to the difference in species of the animal used, differences in doses of the drug administered, and differences in the devices and methods used for the testing. We placed the squirrel monkey at the co-axial center of the rotation (centric rotation) and expected that the response was evoked basically from the hori- 
zontal semicircular canal cristae. Janeke and others, by using eccentric rotation, have demonstrated clear sinusoidal eye movement when there was no nystagmus, while in the present series, no significant eye deviation was evoked by our centric rotation. The dose Janeke and others administered to the rabbit was $0.15 \mathrm{mg}$ (per animal) while our dose was $0.018 \sim 0.045 \mathrm{mg} / \mathrm{kg}$ and therefore, the doses administered per each squirrel monkey were comparatively less. Nevertheless, we observed inhibition of nystagmus.

The pharmaceutical effect of Fentanyl is believed to take place mostly in the reticular formation, thalamus and hypothalamus. The drug seems to involve relatively broad areas of the central nervous system. However, one may expect an inhibitory effect only toward the quick phase (McCabe, 1965; Cohen et al, 1968) of nystagmus and not to other parameters. The drug may also provide different pharmaceutical effects with different animal species. In the present experiment, we administered several different doses of Fentanyl (calibrated by body weight base) and performed the investigation continuously along the postinjection time span until the subject regained the pre-injection functional status. As long as nystagmic eye movement was observed, no significant change in nystagmic wave form was identified. When the nystagmus was inhibited, its frequency declined while the slow phase eye movement remained. These results may coincide with those of Janeke et al. However, inasmuch as no tonic eye deviation was observed in caloric examinations, it is not determinable by the present experiment whether the peripheral activities of both the semicircular canal and otolith end organs were involved or not.

It was previously reported that Fentanyl $(0.1 \mathrm{mg}$, ca $0.014 / \mathrm{kg})$ alone had almost no inhibitory effect on caloric induced nystagmus in humans (Dowdy et $a l, 1965)$. In the present experiment, however, nystagmic inhibition was noticed in six cases after the administration of more than $0.02 \mathrm{mg} / \mathrm{kg}$ of the drug. As far as the pharmaceutical effect is concerned, differences in the doses administered must result in different effects.

\section{REFERENCES}

1. Boedts, D. A. A. and Vendenhove, P. T. E.: Droperidol-Fentanyl citrate in equilibratory disturbances. Arch. Otolaryng. 89: 715-719, 1969

2. Cohen, B.: Komatsuzaki, A. and Bender, M.: Electro-oculographic syndrome in monkeys after pontine reticular formation lesions. Arch. Neurol. 18: 78-92, 1968

3. Dowdy, E. G., Gaksen, N., Arnold, G. E., Moore, W. T. and Fabian, L. W.: A new treatment of Meniere's disease. Arch. Otolaryng. 82: 494-497, 1965

4. Harris, I., Eviator, A. and Goodhill, V.: Droperidol and Fentanyl citrate compound as a vestibular depressant. Arch. Otolaryng. 89: 482-487, 1969 
5. Janeke, J. B., Jongkees, L. B. W. and Oosterveld, W. J.: Selective suppression of the fast phase of labyrinthine nystagmus by Phentanyl (Fentanyl). Acta Otolaryng. 68: $468-473,1969$

6. McCabe, B. F.: The quick component of nystagmus. Laryngoscope 75: 1619-1646, 1965

7. Vancil, M. E., Hemenway, W. G., Spindler, J. and Black F. O.: Suppression of alcohol induced nystagmus by Innovar. Arch. Otolaryng. 90: 482-488, 1969 